\title{
Human Resistin and Cardiovascular Disease
}

\author{
Liu Yuxiang, ${ }^{1}$ MD and Katsuhito Fujiu, ${ }^{1,2}$ MD
}

(Int Heart J 2020; 61: 421-423)

$\mathrm{O}$ besity has become a major worldwide health problem and is involved in multiple diseases, such as insulin resistance, type 2 diabetes, atherosclerosis and ischemic heart disease." Many studies have identified adipocytes or adipose tissue, which were traditionally well-known to have roles in heat insulation, mechanical protection and energy reservoir, and as an endocrine gland that secretes important hormones, cytokines, vasoactive substances and other peptides. ${ }^{2,3}$ Adipocyte biology and systemic metabolism such as in the brain, liver, muscle, and lymphoid organs are influenced by adipocytes or adipose tissue. ${ }^{2)}$ Adipocytes or adipose tissue express and secrete many factors that are referred to as adipokines. ${ }^{2}$ Adipokines have multiple roles, such as in energy homeostasis, glucose and lipid metabolism, thermogenesis control, reproduction, immunity, and cardiovascular function. ${ }^{4)}$ Since resistin was first described in 2001, many studies have examined the relationship between resistin and chronic diseases. Chang, et al. have indicated that the plasma resistin level is associated with plasma tumor necrosis factor (TNF)- $\alpha$, epicardial fat volume and larger left atrial scar. ${ }^{5)}$ A high resistin level is an independent predictor for recurrence of atrial arrhythmia after catheter ablation for atrial fibrillation (AF). Here, we will outline the relationship between resistin and cardiovascular diseases.

\section{Article p.517}

Resistin was discovered by Steppan, et al. as a small circulating mouse protein that was specifically expressed and secreted by adipocytes. ${ }^{6-8)}$ Human resistin is a 12.5 $\mathrm{kDa}$ cysteine-rich polypeptide (108 amino acids) and is the member of a small family of secreted proteins with hormone-like activity which are characterised by a unique spacing of 10-11 cysteine residues and known as resistinlike molecules (RELMs) or as FIZZ (found in inflammatory zone) proteins. ${ }^{69)}$ In humans, the primary source of circulating resistin is secretion by peripheral blood mononuclear cells (PBMCs), macrophages and bone marrow cells. ${ }^{10)}$ Resistin is also secreted by the pituitary gland, hypothalamus, gastrointestinal tract, goblet cells, adrenal glands and other tissues. ${ }^{70-13)}$ Inflammatory conditions are associated with increased levels of circulating resistin. ${ }^{14)}$

Many studies have indicated that resistin was a major cause of atherosclerosis (ATS) and related cardiovascular diseases (CVD), such as heart failure (HF) and cardiac ischemic events. ${ }^{15-17)}$ Resistin also has an anorexic effect leading to a decrease of body mass and an increase of lipogenic enzymes and inflammatory cytokines in the liver ${ }^{18)}$ (Figure).

Thus far, mounting evidence indicates that resistin plays an important role in the genesis of atherosclerotic plaques which lead to focal damage in the blood vessels, promoting ischemic insults and increasing the risk of thrombosis. ${ }^{11,12)}$ In the case of hyper-resistinemia, reactive oxygen species (ROS) are increasingly produced, lowdensity lipoprotein (LDL) is accumulated in the intima of the vessel, and monocytes are recruited, which produce resistin and become foam cells. Endothelial dysfunction in ATS is mediated by the expression of adhesion molecules on the cell surface, secretion of inflammatory and noninflammatory cytokines, and other mechanisms, which play a key role in altering leukocyte adhesion, endothelium permeability and vascular tone control, leading to an atherogenesis-promoting microenvironment. ${ }^{10,12)}$ Resistin mediates endothelial dysfunction by the release of endothelin-1 (ET-1), expression of vascular cell adhesion protein-1 (VCAM-1), intercellular adhesion molecule-1 (ICAM-1), vascular endothelial growth factor receptors (VEGFRs), matrix metalloproteinases (MMPs), and monocyte chemotactic protein-1 (MCP-1); resistin also reduced TNF receptor-associated factor 3 (TRAF3), a key inhibitor of CD40 signaling in endothelial cells. ${ }^{19-21)}$ Meanwhile, endothelial dysfunction increases the expression and production of resistin. ${ }^{22)}$ Resistin can also increase lipid accumulation in macrophages, contributing to foam cell formation. ${ }^{12,23)}$

There is growing evidence indicating that an increase in the circulating resistin level is associated with risk of HF. High serum resistin levels were observed in patients with HF and a high number of cardiac events. ${ }^{24)}$ Several studies investigated the effects of resistin on cardiomyocyte function. Resistin directly impaired glucose uptake in cardiomyocytes by altering vesicle trafficking. ${ }^{25)}$ Resistin expressed in diabetic hearts can promote cardiac hypertro-

From the ${ }^{1}$ Department of Cardiovascular Medicine, Graduate School of Medicine, The University of Tokyo, Tokyo, Japan and ${ }^{2}$ Department of Advanced Cardiology, Graduate School of Medicine, The University of Tokyo, Tokyo, Japan.

Address for correspondence: Katsuhito Fujiu, MD, Department of Cardiovascular Medicine, Graduate School of Medicine, The University of Tokyo, 7-3-1 Hongo, Bunkyo-ku, Tokyo 113-8655, Japan. E-mail: fujiu-tky@umin.ac.jp

Received for publication March 26, 2020. Revised and accepted March 26, 2020.

doi: 10.1536/ihj.20-221

All rights reserved by the International Heart Journal Association. 


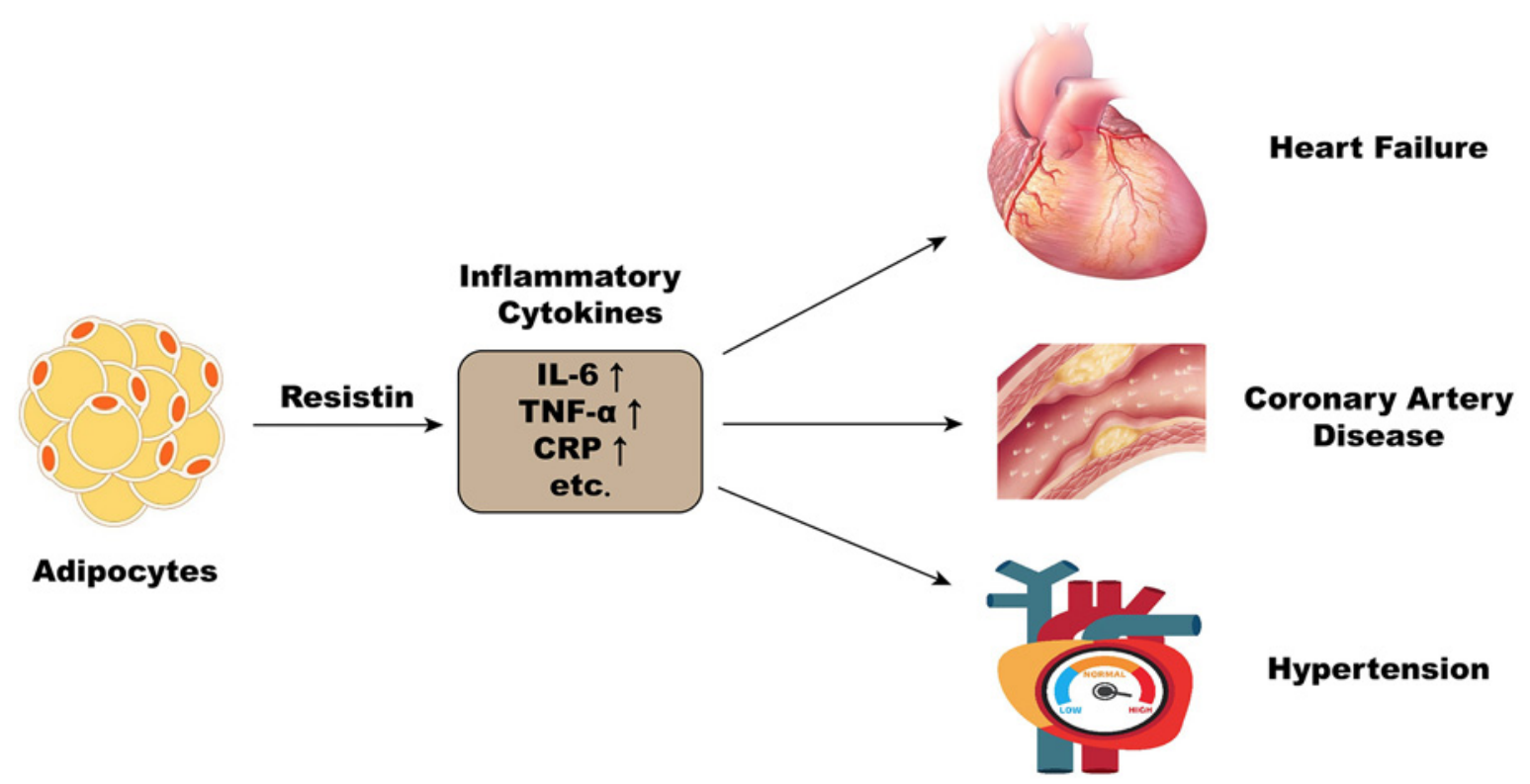

Figure. Overview of cardiovascular effects of resistin.

phy and depress myocyte contractility. ${ }^{26)}$ In cultured rat neonatal cardiomyocytes, the expression of resistin was also increased by mechanical stretch. ${ }^{27)}$ However, until now, whether human resistin has direct pathogenic effects on HF development and aggravation has not been tested.

Several experimental and clinical studies have highlighted a relationship between resistin and hypertension. In a clinical study, Zhang, et al. found that higher blood resistin levels were correlated with a raised risk for incidents of hypertension among women without diabetes. ${ }^{28)}$ Although the precise mechanisms by which resistin affects blood pressure is not clear, several mechanisms have been proposed. Potential mechanisms linking resistin to hypertension include the vasoconstrictor property of resistin, promoting smooth muscle cell proliferation, and effects on the renin-angiotensin system (RAS). ${ }^{29,30)}$

Although a specific receptor for human resistin has not been fully identified yet, considering that resistin is associated with various cardiovascular diseases, solving these obstacles one by one will provide insight into these molecules not only with respect to cardiovascular diseases but also metabolic and other disorders.

\section{Disclosure}

Conflicts of interest: None.

\section{References}

1. Ouchi N, Parker JL, Lugus JJ, Walsh K. Adipokines in inflammation and metabolic disease. Nat Rev Immunol 2011; 11: 8597.

2. Lee SE, Kim HS. Human resistin in cardiovascular disease. J Smooth Muscle Res 2012; 48: 27-35.

3. Smekal A, Vaclavik J. Adipokines and cardiovascular disease: A comprehensive review. Biomed Papers 2017; 161: 31-40.

4. Gualillo O, Gonzalez-Juanatey JR, Lago F. The emerging role of adipokines as, mediators of cardiovascular function: Physiologic and clinical perspectives. Trends Cardiovas Med 2007; 17: 27583.

5. Chang TY, Hsiao YM, Guo SM, et al. Resistin as a biomarker for prediction of left atrial substrate and recurrence in patients with drug-refractory atrial fibrillation undergoing catheter ablation. Int Heart J 2020; 61: 517-23.

6. Steppan CM, Brown EJ, Wright CM, et al. A family of tissuespecific resistin-like molecules. Proc Natl Acad Sci U S A 2001; 98: 502-6.

7. Steppan CM, Lazar MA. Resistin and obesity-associated insulin resistance. Trends Endocrinol Metab 2002; 13: 18-23.

8. Kim KH, Lee K, Moon YS, Sul HS. A cysteine-rich adipose tissue-specific secretory factor inhibits adipocyte differentiation. J Biol Chem 2001; 276: 11252-6.

9. Steppan CM, Bailey ST, Bhat S, et al. The hormone resistin links obesity to diabetes. Nature 2001; 409: 307-12.

10. Codoner-Franch P, Alonso-Iglesias E. Resistin: insulin resistance to malignancy. Clin Chim Acta 2015; 438: 46-54.

11. Filkova M, Haluzik M, Gay S, Senolt L. The role of resistin as a regulator of inflammation: Implications for various human pathologies. Clin Immunol 2009; 133: 157-70.

12. Jamaluddin MS, Weakley SM, Yao QZ, Chen CY. Resistin: functional roles and therapeutic considerations for cardiovascular disease. Brit J Pharmacol 2012; 165: 622-32.

13. Rajala MW, Obici S, Scherer PE, Rossetti L. Adipose-derived resistin and gut-derived resistin-like molecule-beta selectively impair insulin action on glucose production. J Clin Invest 2003; 111: $225-30$

14. Lehrke M, Reilly MP, Millington SC, Iqbal N, Rader DJ, Lazar MA. An inflammatory cascade leading to hyperresistinemia in humans. PLoS Med 2004; 1: e45.

15. Burnett MS, Lee CW, Kinnaird TD, et al. The potential role of resistin in atherogenesis. Atherosclerosis 2005; 182: 241-8.

16. Reilly MP, Lehrke M, Wolfe ML, Rohatgi A, Lazar MA, Rader DJ. Resistin is aninflammatory marker of atherosclerosis in humans. Circulation 2005; 111: 932-9.

17. Cheng JM, Akkerhuis KM, Battes LC, et al. Biomarkers of heart failure with normal ejection fraction: a systematic review. Eur J Heart Fail 2013; 15: 1350-62.

18. Vázquez MJ, González CR, Varela L, et al. Central resistin regulates hypothalamic and peripheral lipid metabolism in a 
nutritional-dependent fashion. Endocrinology 2008; 149: 453443.

19. Anderson PD, Mehta NN, Wolfe ML, et al. Innate immunity modulates adipokines in humans. J Clin Endocrinol Metab 2007; 92: 2272-9.

20. Verma S, Li SH, Wang $\mathrm{CH}$, et al. Resistin promotes endothelial cell activation: further evidence of adipokine-endothelial interaction. Circulation 2003; 108: 736-40.

21. Kawanami D, Maemura K, Takeda N, et al. Direct reciprocal effects of resistin and adiponectin on vascular endothelial cells: a new insight into adipocytokine-endothelial cell interactions. Biochem Biophys Res Commun 2004; 314: 415-9.

22. Lefterova MI, Mullican SE, Tomaru T, Qatanani M, Schupp M, Lazar MA. Endoplasmic reticulum stress regulates adipocyte resistin expression. Diabetes 2009; 58: 1879-86.

23. Rae C, Graham A. Human resistin promotes macrophage lipid accumulation. Diabetologia 2006; 49: 1112-4.

24. Takeishi Y, Niizeki T, Arimoto T, et al. Serum resistin is associated with high risk in patients with congestive heart failure--a novel link between metabolic signals and heart failure. Circ J 2007; 71: 460-4.

25. Graveleau C, Zaha VG, Mohajer A, et al. Mouse and human re- sistins impair glucose transport in primary mouse cardiomyocytes, and oligomerization is required for this biological action. J Biol Chem 2005; 280: 31679-85.

26. Kim M, Oh JK, Sakata S, et al. Role of resistin in cardiac contractility and hypertrophy. J Mol Cell Cardiol 2008; 45: 270-80.

27. Wang BW, Hung HF, Chang H, Kuan P, Shyu KG. Mechanical stretch enhances the expression of resistin gene in cultured cardiomyocytes via tumor necrosis factor-alpha. Am J Physiol Heart Circ Physiol 2007; 293: H2305-12.

28. Zhang LX, Curhan GC, Forman JP. Plasma Resistin Levels Associate with Risk For Hypertension among Nondiabetic Women. J Am Soc Nephrol 2010; 21: 1185-91.

29. Teng X, Li D, Champion HC, Johns RA. FIZZ1/RELMalpha, a novel hypoxia-induced mitogenic factor in lung with vasoconstrictive and angiogenic properties. Circ Res 2003; 92: 1065-7.

30. Calabro P, Samudio I, Willerson JT, Yeh ET. Resistin promotes smooth muscle cell proliferation through activation of extracellular signal-regulated kinase $1 / 2$ and phosphatidylinositol 3kinase pathways. Circulation 2004; 110: 3335-40. 